\title{
ADUBAÇÃO DO CAFEEIRO COM NITRATO DE POTÁSSIO VIA SOLO E FOLHA, NO OUTONO-INVERNO E PRIMAVERA-VERÃO: EFEITOS NA ATIVIDADE DA REDUTASE DO NITRATO, NO CRESCIMENTO DAS PLANTAS E NA PRODUÇÃO
}

\author{
Coffee tree fertilization with potassium nitrate via leaf and soil, in autumn-winter and \\ spring-summer: effects on nitrate reductase activity, on plant growth and production
}

\author{
Rupert Barros de Freitas', José Donizeti Alves², Marcelo Murad Magalhães ${ }^{3}$, Patrícia de Fátima Pereira Goulart4, \\ Marilza Neves do Nascimento ${ }^{5}$, Daniela Deitos Fries ${ }^{3}$
}

\begin{abstract}
RESUMO
Objetivou-se verificar o efeito da adubação de $100 \mathrm{~g}$ de N/ano/planta, em três épocas (outono-inverno, primavera-verão e outono-inverno/primavera-verão) e três modos de aplicação (folha, solo e folha/solo), no desenvolvimento, na produção e na atividade da redutase do nitrato (RN) da cultivar Rubi-MG com quatro anos de idade. A análise conjunta entre o modo e época de aplicação mostra que o padrão de RN não se altera, sendo no frio maior nas raízes e no calor maior nas folhas. $\mathrm{O}$ mesmo aconteceu com o padrão de crescimento, rápido na estação quente/chuvosa e lento no período seco/frio. Em função da época de adubação, concluiu-se que, no outono-inverno, deve-se dar preferência pela aplicação na folha ou folha-solo. Esses modos de adubação foram os mais eficientes na retomada do crescimento. Quando as adubações ocorrerem nos dois períodos, qualquer um dos três modos pode ser utilizado. Apesar da inviabilidade de várias pulverizações, eventualmente, uma ou mais pulverizações com $\mathrm{KNO}_{3}$ podem substituir eficientemente a adubação no solo.
\end{abstract}

Termos para indexação: Cafeeiro, pulverização com nitrato de potássio, redutase do nitrato, crescimento, produtividade, Coffea arabica.

\begin{abstract}
The objective of this work was to verify the effect of the fertilization of $100 \mathrm{~g} \mathrm{~N} / \mathrm{year} / \mathrm{plant}$, in three periods (autumn-winter, spring-summer and autumn-winter/spring-summer) and three types of application (leaf, soil and leaf/soil) on the development, production and nitrate reductase activity (NR) on four years old Rubi-MG cultivar. The analysis of type and time of application showed no alteration on NR activity being higher on roots in cold weather and higher on leaves in warmer weather. The same was observed with growth pattern, fast in hot/rain season and slow in dry/cold period. During autumn-winter, applications may be performed on leaf or leaf-soil. These types of fertilization were the most efficient during growth recovering. When the fertilization occurred in both periods, any type may be used. Although, several pulverizations are nonviable, one or more pulverization with $\mathrm{KNO}_{3}$ can efficiently replace soil fertilization.
\end{abstract}

Index terms: Coffee, potassium nitrate fertilization, nitrate reductase, growth, yield, Coffea arabica.

(Recebido em 4 de novembro de 2005 e aprovado em 23 de maio de 2006)

\section{INTRODUÇÃO}

A utilização de adubações foliares nitrogenadas para a cultura do café tem sido considerada ineficiente, visto que as plantas não são capazes de manter o mesmo padrão de crescimento, desenvolvimento e produção em relação às plantas supridas com esse macronutrientes no solo. Garcia et al. (1983) mostraram que o nitrogênio, quando aplicado nas folhas, na fase de formação ou na fase de produção, não atendeu à demanda do cafeeiro
(Coffea arabica L.), refletindo de forma negativa. Com isso, concluíram que este nutriente deve ser aplicado no solo. Santinato \& Pereira (1996) comprovaram esta afirmação ao estudarem os efeitos da aplicação de soluções de nitrato de potássio via foliar, não encontrando resultados significativos para o aumento na produção. De maneira semelhante, Santinato \& Camargo (1989), por não encontrarem efeitos benéficos no desenvolvimento e na produção dos cafeeiros submetidos às suplementações

Professor Dr., Fundação Comunitária de Ensino Superior de Itabira - Rodovia MG03 - Córrego Seco - Areão - $35900-972$ - Itabira, MG rupert.freitas@funcesi.br

${ }^{2}$ Professor Dr., no setor de Fisiologia Vegetal do Departamento de Biologia/DBI da Universidade Federal de Lavras/UFLA - Cx. P. 3037 - $37200-000$ Lavras, MG - jdalves@ufla.br

${ }^{3}$ Dr., pelo setor de Fisiologia Vegetal do Departamento de Biologia/DBI da Universidade Federal de Lavras/UFLA - Cx. P. 3037 - $37200-000$ - Lavras, MG mmurad@ufla.br; friesdd@ufla.br

${ }^{4}$ Dra., Professora do Centro Universitário de Lavras/Unilavras - Rua Padre José Poggel, 506 - Centenário - $37200-000$ - Lavras, MG patriciagoulart@unilavras.edu.br

${ }^{5}$ Doutoranda no Setor de Fisiologia Vegetal do Departamento de Biologia/DBI da Universidade Federal de Lavras/UFLA - Cx. P. 3037 - $37200-000$ Lavras, MG - marilzaagro@hotmail.com 
foliares de N, P e K, sugeriram que quando estas plantas são adubadas no solo de forma equilibrada, a adubação foliar torna-se dispensável.

$\mathrm{Na}$ maioria das pesquisas realizadas, em que se desqualificou a eficiência da aplicação nitrogenada foliar ao cafeeiro, foram utilizados adubos na concentração de $2 \%$, com um volume de calda de $300 \mathrm{~mL}$ por planta. Nessas condições, os cálculos teóricos realizados por Rena \& Fávaro (2000) mostraram que a quantidade de N aplicada seria insuficiente para suprir as necessidades desse nutriente. Uma alternativa seria a de aumentar a concentração do sal. Entretanto, a aplicação de adubos nitrogenados em concentrações elevadas sofre sérias limitações pelo fato de que, dependendo da força iônica da solução, concentrações superiores a 2,5\%, normalmente causam uma grande queima das folhas e brotações (MALAVOLTA, 1980). Entretanto, estudos preliminares mostraram que a pulverização de cafeeiros com nitrato de potássio até $25 \%$, além de não provocar necroses significativas ou modificação na morfologia foliar, estimulou a atividade da redutase do nitrato naquele órgão (NASCIMENTO et al., 2004). Essa enzima, que é chave no metabolismo do nitrato, é altamente modulada por fatores extremos do ambiente, como luz, temperatura e água, assim como sua síntese e atividade são induzidas pelo próprio substrato.

Desse modo, pesquisas mais aprofundadas, principalmente a verificação dos efeitos da pulverização com esse adubo em altas concentrações no desenvolvimento vegetativo e reprodutivo do cafeeiro se fazem necessárias, a fim de validar o uso dessa técnica.

Pelo exposto, buscou-se neste trabalho, verificar o efeito da adubação de nitrato de potássio, em três épocas e em três modos de aplicação, avaliando-se a sua influência no desenvolvimento da planta, na atividade da redutase do nitrato foliar e radicular e na produção.

\section{MATERIAL E MÉTODOS}

O trabalho foi conduzido em uma lavoura de café da cultivar Rubi MG, com aproximadamente quatro anos, implantada no espaçamento de 3,5 m x 0,8 m e cultivada a pleno sol. A área experimental, cujo solo foi classificado como Latossolo Vermelho Escuro Distrófico, com declividade média de $8 \%$, está situada em Lavras, Minas Gerais, a $918 \mathrm{~m}$ de altitude, $21^{\circ} 14$ 'S de latitude e longitude 44,900' W GRW. Até a instalação do experimento, a lavoura estava sendo adubada de acordo com as Recomendações para o Uso de Corretivos e Fertilizantes em Minas Gerais (RIBEIRO et al., 1999).
Durante a condução do experimento, foi realizado o controle de pragas, doenças e de plantas daninhas, e manteve-se a mesma adubação, exceto para o nitrogênio, cuja dose foi de $100 \mathrm{~g}$ de N/ano/planta, em três épocas (outono-inverno; primavera-verão; outono-inverno e primavera-verão) e em três modos de aplicação (na folha; no solo; na folha e no solo), totalizando nove tratamentos (Tabela 1). Os tratamentos foram distribuídos em quatro blocos ao acaso, com uma unidade experimental formada por três plantas úteis.

Foram tomados, mensalmente, o comprimento e o número de nós em dois ramos plagiotrópicos voltados para os dois lados da rua, no terço superior da copa. Nestas mesmas ocasiões foram mensuradas a largura e o comprimento de duas folhas por planta que, depois de multiplicados entre si e por 0,667 (BARROS et al., 1973) determinaram os valores da área foliar.

A temperatura do ar e a precipitação pluvial foram obtidas na estação meteorológica situada a aproximadamente $300 \mathrm{~m}$ do experimento. A temperatura do solo, nas profundidades de 0,10 e $0,20 \mathrm{~m}$, foi determinada na região correspondente à projeção da copa do cafeeiro, nos horários compreendidos entre 9:00 e 10:00 h e 14:00 e 15:00 h, utilizando-se um sensor de temperatura do solo LI 1400-103 acoplado a um sistema de registro LI-1400.

O nitrato do solo foi quantificado em amostra simples de solo, coletada a profundidade de 0-20 cm, em cada repetição, na projeção da copa dos cafeeiros de acordo com a metodologia proposta por Bremner (1965) e Keeneu \& Nelson (1982).

A atividade da Redutase do Nitrato (RN), enzima que catalisa a redução de nitrato a nitrito, foi determinada conforme a metodologia descrita por Alves et al. (1985) e Queiroz (1986) em amostras de sete folhas e $100 \mathrm{mg}$ de raízes coletadas as 9:00 horas e às 14:00 horas, respectivamente, 48 horas após os cafeeiros receberem adubação com nitrato de potássio.

A produtividade expressa foi determinada com base na produção de cinco plantas por repetição.

\section{RESULTADOS E DISCUSSÃO}

Quando a adubação com nitrato de potássio foi realizada na primavera-verão (outubro a março) (Figura 1a), observou-se para esse mesmo período, maiores atividades da RN foliar em relação ao período anterior de outonoinverno (abril a setembro) e essas foram, em ordem decrescente, proporcionadas pelos tratamentos de aplicação do adubo na folha-solo, na folha, e somente no solo. Estes resultados mostram que houve uma eficiente 
TABELA 1 - Tratamentos formados a partir das épocas, dos locais e das quantidades de nitrogênio aplicadas, na forma de nitrato de potássio.

\begin{tabular}{|c|c|c|}
\hline \multicolumn{2}{|c|}{ Adubação } & \multirow{2}{*}{$100 \mathrm{~g} \mathrm{~N} /$ planta } \\
\hline Época & Local & \\
\hline \multirow{3}{*}{$\begin{array}{c}\text { Outono-inverno } \\
\text { (Abr, Jun, Jul, Ago e } \\
\text { Set) }\end{array}$} & Solo & $20 \mathrm{~g}$ a cada 30 dias \\
\hline & Folha* & $10 \mathrm{~g}$ a cada 15 dias \\
\hline & Folha $^{* *}$ / Solo & $4 \mathrm{~g}$ na folha e $16 \mathrm{~g}$ no solo, a cada 30 dias \\
\hline \multirow{3}{*}{$\begin{array}{c}\text { Primavera-verão } \\
\text { (Out, Nov, Jan, Fev } \\
\text { e } \\
\text { Mar) }\end{array}$} & Solo & $20 \mathrm{~g}$ a cada 30 dias \\
\hline & Folha ${ }^{*}$ & $10 \mathrm{~g}$ a cada 15 dias \\
\hline & Folha** / Solo & $4 \mathrm{~g}$ na folha e $16 \mathrm{~g}$ no solo, a cada 30 dias \\
\hline \multirow{3}{*}{$\begin{array}{l}\text { Outono-inverno/ } \\
\text { Primavera-verão }\end{array}$} & Solo & $10 \mathrm{~g}$ a cada 30 dias \\
\hline & Folha* & $10 \mathrm{~g}$ a cada 30 dias \\
\hline & Folha* / Solo & $2 \mathrm{~g}$ na folha e $8 \mathrm{~g}$ no solo a cada 30 dias \\
\hline
\end{tabular}

*Cada pulverização resultou na aplicação de solução de nitrato de potássio preparada a uma concentração de $25 \%$, sendo gastos, em média, 300 mL de solução por planta, tomando-se o cuidado de evitar escorrimento da solução para o solo.

** Correspondente a uma solução a $10 \%$ de nitrato de potássio.

absorção do nitrato pelas folhas e indução da enzima por este ânion, uma vez que se relacionam com a dose e o local de aplicação. Da mesma forma, mostram também que o nitrogênio aplicado no solo foi translocado para a folha, induzindo, portanto, a ativação da enzima pelo substrato. Elevações da temperatura do ar e das precipitações pluviométricas, associadas à adubação com o nitrato, provavelmente contribuíram para o aumento da atividade da RN entre outubro e março. Durante esses meses, as temperaturas médias do ar permaneceram próximas a $25^{\circ} \mathrm{C}$ e as mínimas situaram-se acima de $15^{\circ} \mathrm{C}$, o que, de acordo com o trabalho de Amaral (1991), se mostraram satisfatórias para a assimilação do nitrato nas folhas de cafeeiros.

Para o mesmo período de adubação e avaliação (primavera-verão) observou-se, em relação à atividade da RN nas raízes (Figura 1d), que os tratamentos não diferiram. Dessa forma, não foi verificada a mesma relação entre dose e local de aplicação do adubo. Embora as temperaturas do solo tenham permanecido próximo a $25^{\circ} \mathrm{C}$, o que é considerado adequado para a atividade dessa enzima
(AMARAL, 1991), a atividade radicular da RN foi considerada baixa e caiu em relação ao período anterior (outono-inverno), possivelmente em função de perdas de $\mathrm{NO}_{3}^{-}$provocadas por fortes precipitações pluviométricas ocorridas entre outubro e março. No entanto, não se pode descartar a possibilidade de uma alternância de atividade da enzima entre folhas e raízes, nos períodos estudados, mediada pelas temperaturas do ar e do solo e pela concentração de $\mathrm{NO}_{3}^{-}$nos órgãos. Dessa forma, como se verá mais adiante, para as outras duas épocas de aplicação do adubo, uma alta atividade da RN na folha sempre coincidiu com uma baixa atividade nas raízes e vice-versa.

Em resposta à adubação realizada no período de outono-inverno (Figura 1b), observou-se que, entre abril e setembro, a atividade da RN nas folhas não sofreu influência das diferentes formas de aplicação do adubo e nem mesmo foi estimulada por ela. Esses resultados podem ser creditados às baixas temperaturas do ar observadas nessa época, uma vez que nesse período, os valores encontrados são bastante semelhantes àqueles verificados 
nas folhas de cafeeiros que seriam adubados somente na primavera-verão (Figura 1a).

As diferentes formas de adubação de outonoinverno também não promoveram influências no padrão de resposta da $\mathrm{RN}$ foliar no período posterior de primaveraverão (Figura 1b). O que se observa é que, de outubro em diante, as folhas tiveram a atividade da enzima aumentada, possivelmente em função de elevações na temperatura do ar e da manutenção de níveis de $\mathrm{NO}_{3}^{-}$nas folhas próximos aos adequados, já que, quantitativamente, os valores de atividade alcançados nessa época, não atingiram o patamar daqueles encontrados quando a adubação foi realizada na primavera-verão (Figura 1a).

$\mathrm{Na}$ raiz, os modos de aplicação do nitrato de potássio não proporcionaram diferenças na atividade da $\mathrm{RN}$, durante o outono e inverno (Figura 1e). O que se observou, entretanto, é que, durante esse período, a atividade da enzima permaneceu alta e, posteriormente, na primavera-verão, ela diminuiu. Este padrão de resposta mostrou que, nos meses de abril a setembro, a temperatura do solo não foi limitante como a do ar, já que não atingiu valores inferiores a $15^{\circ} \mathrm{C}$. Portanto, o estímulo na atividade da $\mathrm{RN}$ radicular no outonoinverno em relação à primavera-verão, deve-se à presença do seu substrato tendo como fonte o adubo aplicado diretamente no solo ou translocado da parte-aérea para a raiz, quando a aplicação foi feita nas folhas. Esta última observação pode ser constatada, ao verificar que a atividade da enzima nas raízes de plantas que foram pulverizadas com o nitrato foi semelhante àquelas encontradas nas de plantas adubadas no solo ou na folha-solo. No período de primaveraverão, a atividade da $\mathrm{RN}$ caiu com um todo, possivelmente devido à lixiviação de $\mathrm{NO}_{3}^{-}$provocada pelas fortes chuvas.

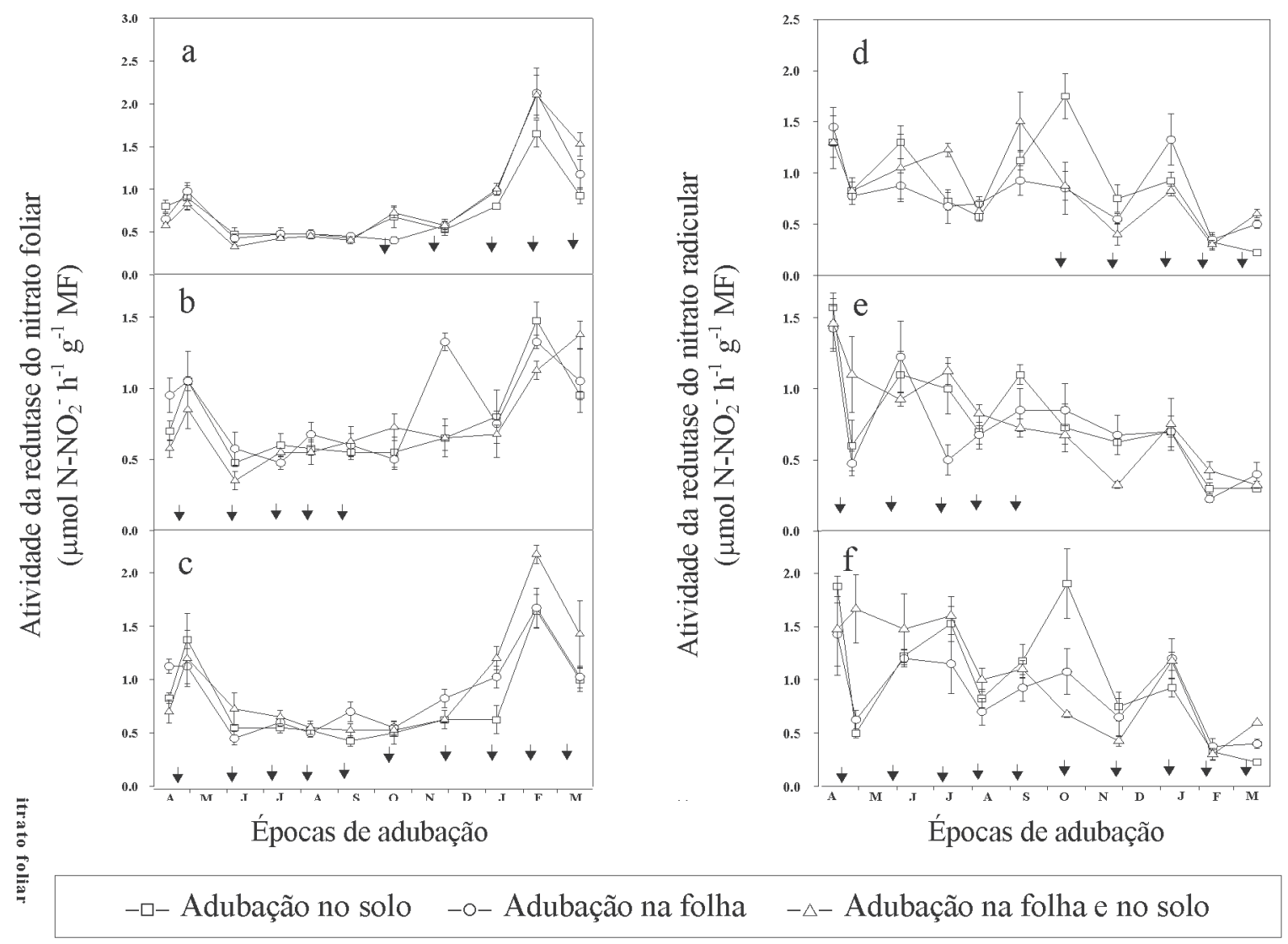

FIGURA 1 - Atividade da redutase do nitrato foliar (a, b, c) e radicular (d, e, f) de cafeeiros supridos com N no solo, na folha, e na folha-solo, nos períodos de primavera-verão (a, d), outono-inverno (b, e) e outono-inverno/primavera-verão $(c, f)$. (as barras representam o erro padrão da média de quatro repetições e as setas, os meses em que os cafeeiros foram adubados).

Ciênc. agrotec., Lavras, v. 31, n. 4, p. 945-952, jul./ago., 2007 
Em relação à adubação nas duas épocas do ano (outono-inverno e primavera-verão), o padrão de resposta, tanto da atividade foliar (Figura 1c) quanto radicular (Figura 1f) da $\mathrm{RN}$, foi o mesmo daquele encontrado quando a adubação foi realizada somente no outono-inverno (Figuras 1b e 1e). É importante ressaltar que em todos os casos, a pulverização dos cafeeiros não aumentou a concentração de $\mathrm{NO}_{3}^{-}$no solo (dados não apresentados), o que comprova, juntamente com os resultados de nitrogênio nas folhas, que o nitrogênio aplicado nas folhas, ali permaneceu durante o processo de absorção, não tendo escorrido para o solo.

$\mathrm{O}$ efeito de diferentes modos de adubação com nitrato de potássio nos períodos de primavera-verão mostrou que a aplicação do nitrato na folha-solo e no solo proporcionou, na maioria das avaliações realizadas entre outubro e março, maior crescimento dos ramos plagiotrópicos (Figura 2a) e de número de nós (Figura 2d). No outono-inverno (Figuras $2 \mathrm{~b}$ e $2 \mathrm{e}$ ) e outono-inverno/ primavera-verão (Figuras 2c e 2f), os maiores valores de

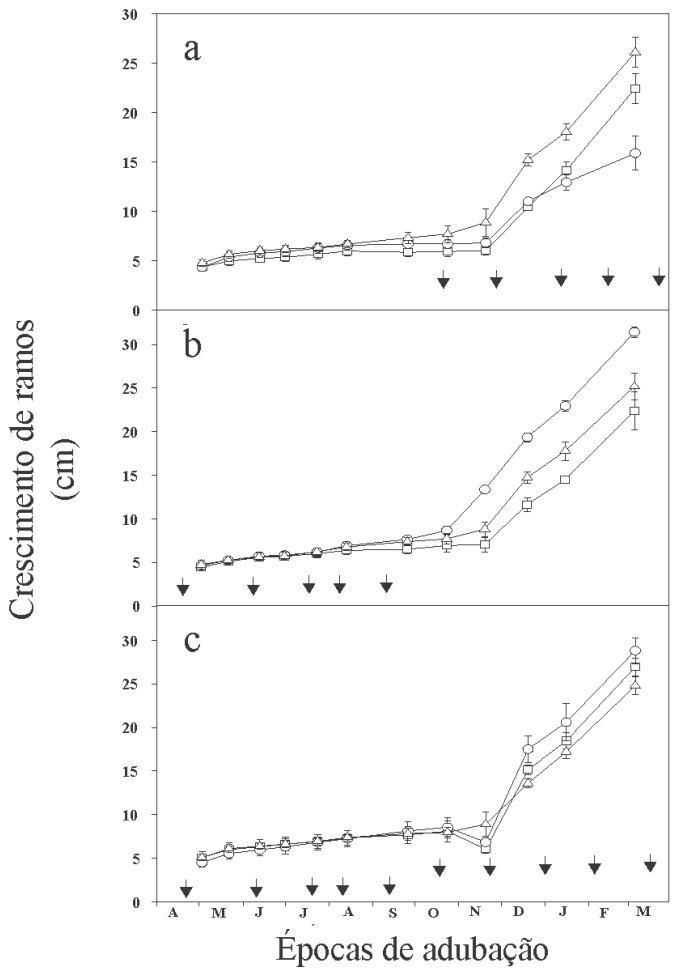

comprimento de ramo e de número de nós na época de crescimento ativo foram verificados quando a adubação ocorreu na folha e na folha-solo. A superioridade do tratamento empregado, quando da ação conjugada da aplicação do nitrato de potássio na folha-solo sobre o crescimento vegetativo do cafeeiro, corrobora aqueles verificados por Camargo \& Silva (1975), que propuseram substituir $20 \%$ da adubação de solo pela via foliar, divididos em três pulverizações. Com relação ao crescimento das folhas, embora obedecendo o mesmo padrão, não foram observadas diferenças em relação aos três modos de aplicação do adubo (dados não apresentados).

É importante destacar que a despeito da concentração de $25 \%$ da solução, observou-se em função da aplicação foliar na primavera-verão, deposição do sal nas folhas, sem, no entanto, causar queima significativa nas mesmas. Do mesmo modo, a aplicação do adubo foliar nas estações de outono-inverno, causou nos dias que sucederam a aplicação, pequenas necroses nas folhas, que desapareceram no período de primavera-verão, não

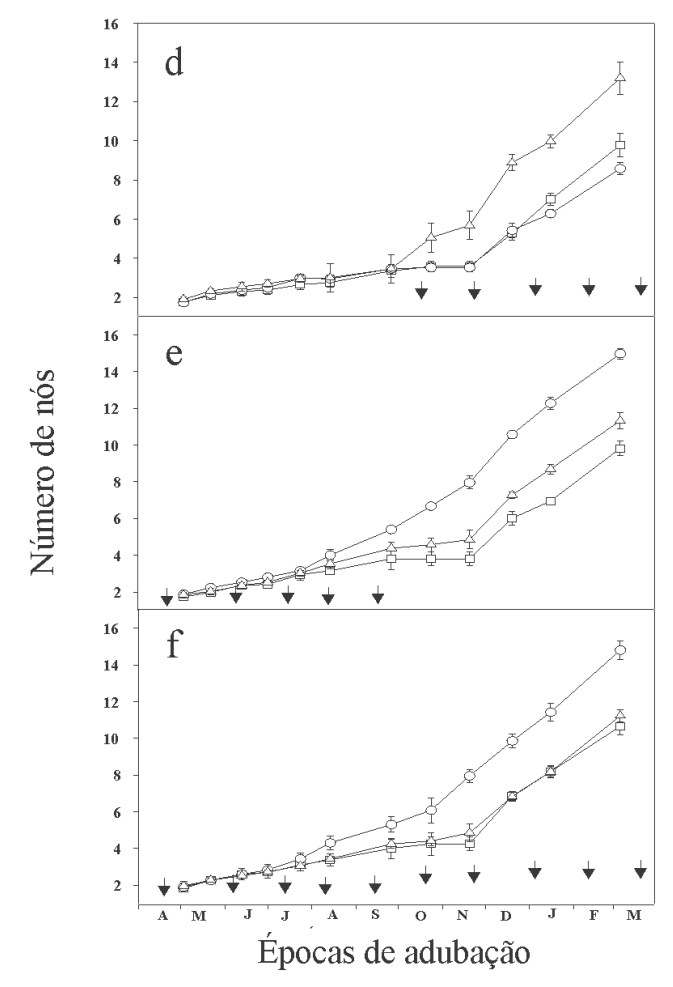

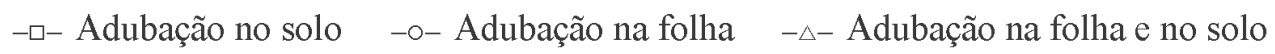

FIGURA 2 - Crescimento de ramos plagiotrópicos (a, b, c) e número de nós (d, e, f) de cafeeiros supridos com N no solo, na folha, e na folha-solo, nos períodos de primavera-verão (a, d), outono-inverno (b, e) e outono-inverno/primaveraverão (c, f). (as barras representam o erro padrão da média de quatro repetições de doze ramos cada e as setas, os meses em que os cafeeiros foram adubados).

Ciênc. agrotec., Lavras, v. 31, n. 4, p. 945-952, jul./ago., 2007 
influenciando desse modo, o desenvolvimento das plantas, no período de primavera-verão. Essas observações são corroboradas ao verificar que as plantas que receberam, nos meses de abril a setembro, nitrato de potássio nas folhas, seguidas por aquelas que o receberam na folhasolo, e as que receberam a adubação nas folhas-solo no período de outubro a março, foram as que apresentaram as maiores taxas de crescimento dos ramos nas estações de primavera-verão. Desse modo, os resultados demonstraram que as adubações nitrogenadas nas folhas trazem efeitos benéficos na retomada do crescimento vegetativo do cafeeiro no período de primavera-verão a despeito de dados da literatura que mostram que a pulverização de adubos nitrogenados não é eficiente para garantir um adequado desenvolvimento do cafeeiro (SANTINATO \& PEREIRA, 1996). Nossos resultados mostram, que a adubação nitrogenada foliar, em altas concentrações (25\%), estimula o desenvolvimento vegetativo em taxas, consideravelmente, altas para o período de crescimento ativo do cafeeiro, entre setembro e março.

A capacidade do cafeeiro de reduzir o nitrato na raiz e na folha, explica a superioridade dos resultados encontrados, pela partição do nitrato de potássio entre os dois órgãos. No período de inverno, onde as temperaturas do ar são limitantes para a atividade foliar da $\mathrm{RN}$, prevalece a atividade radicular, onde as temperaturas são mais elevadas. Na primavera-verão, com o aumento da temperatura do ar próximo a $28^{\circ} \mathrm{C}$, a atividade da $\mathrm{RN}$ na folha é estimulada, passando a prevalecer sobre as raízes. Esses resultados demonstraram que a distribuição da atividade da $\mathrm{RN}$ entre raízes e folhas do cafeeiro se alternam entre os períodos de frio e de calor. Além disso, observouse que o crescimento do cafeeiro não se relaciona isoladamente com o metabolismo do nitrato na raiz ou na folha e, sim é dependente do conjunto. Portanto, a eficiência da aplicação do nitrato de potássio na folha-solo, ao estimular o metabolismo do $\mathrm{N}$ nos dois órgãos, proporciona maiores ganhos de matéria seca do que o seu estímulo somente em uma das duas partes da planta.

Uma análise conjunta entre o modo de aplicação do adubo nitrogenado e a época de aplicação mostra que o padrão de atividade da RN não se altera. No frio a atividade da $\mathrm{RN}$ prevalece nas raízes enquanto que no calor, a da folha é que se destaca. O mesmo acontece com o padrão sazonal de crescimento. Observou-se um crescimento rápido em meados de setembro até março, caracterizado pela estação quente e chuvosa, seguido de um crescimento lento de abril a agosto, durante o período seco e frio.

Os resultados também validam ao que Amaral (1991) observou em sua pesquisa em que a adubação nitrogenada de outono-inverno estimula o crescimento vegetativo do cafeeiro nos períodos de primavera-verão. Em relação ao metabolismo do nitrogênio, a vantagem parece estar ligada à capacidade das plantas de café sintetizarem, nas folhas e raízes a $\mathrm{RN}$, uma enzima chave do metabolismo no nitrato, altamente modulada pelos fatores extremos de ambiente como a luz, temperatura e água, entre outros.

No caso em particular, as plantas, independentemente de terem recebido ou não o adubo nitrogenado, mostraram, durante o período de frio, uma paralisação do metabolismo do nitrogênio nas folhas, provavelmente em função da queda da temperatura mínima do ar abaixo de $12,5^{\circ} \mathrm{C}$. Por outro lado, aquelas que foram adubadas, via solo ou folha, com nitrogênio no outonoinverno apresentaram, durante este mesmo período de frio, uma elevada atividade da enzima na raiz, uma vez que nesta época a temperatura do solo, em momento algum ficou abaixo de $15^{\circ} \mathrm{C}$ (Figura 1). Portanto, as raízes dos cafeeiros que receberam o nitrogênio suplementar no inverno, seja via direta no solo ou translocado das folhas, possuíam, além de RN mais ativas, um maior número de moléculas dessas enzimas por unidade de volume, uma vez que sua síntese é altamente induzida pelo substrato. Neste ponto é importante destacar que o crescimento das raízes do cafeeiro em relação à parte aérea é autônomo e quase sempre precede o crescimento da parte aérea. Portanto, a adição de nitrogênio suplementar no período de frio, principalmente via folha (Figura 2) exerce um efeito estimulante no crescimento, como conseqüência da formação de metabólitos nitrogenados orgânicos sintetizados e acumulados nas raízes durante o inverno, o que suporta maior demanda de crescimento da parte aérea nas estações subseqüentes.

Em função da época de adubação nitrogenada, os resultados da análise das produções permitiram concluir que, no outono-inverno (Figura 3a), deve-se dar preferência pela pulverização de toda a dose do fertilizante na folha ou aplicação de $80 \%$ do nitrato de potássio no solo e o restante suplementado via foliar. Estes dois modos de adubação foram também os mais eficientes na retomada do crescimento vegetativo (Figuras $2 b$ e $2 e$ ). Se a adubação de solo no período de primavera-verão (Figura $3 b$ ) for considerada como o padrão, a adubação de parte do adubo na folha e parte no solo também deve ser a preferida, inclusive porque proporcionaram maiores taxas de crescimento vegetativo (Figuras $2 \mathrm{a}$ e $2 \mathrm{~d}$ ). Por outro lado, qualquer um dos três modos de aplicação do nitrato de potássio pode ser utilizado quando as adubações ocorrerem

Ciênc. agrotec., Lavras, v. 31, n. 4, p. 945-952, jul./ago., 2007 


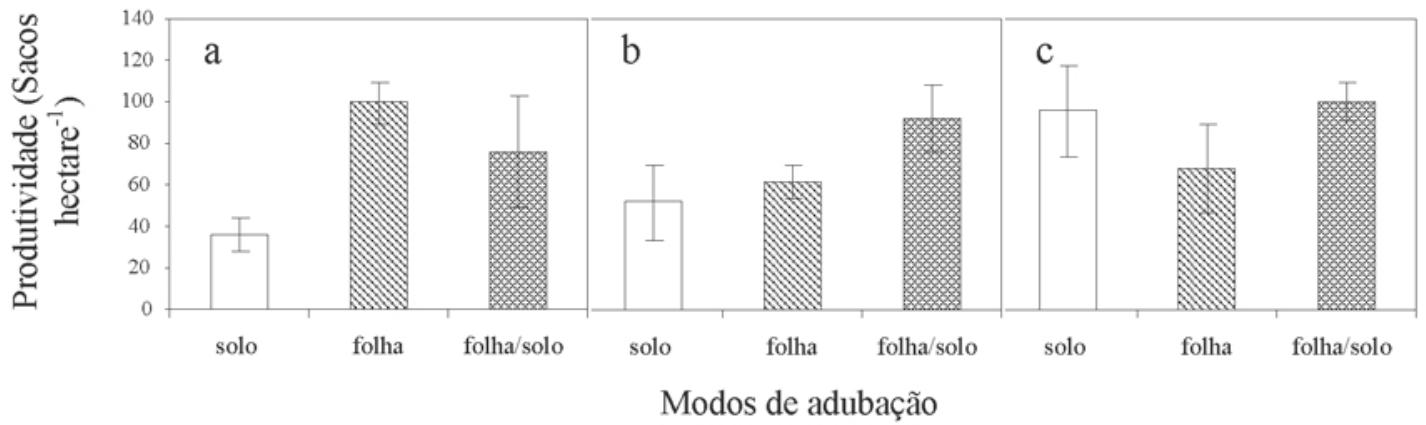

FIGURA 3 - Produtividade do cafeeiro em função dos diferentes modos de aplicação do nitrato de potássio no outonoinverno (a), primavera-verão (b), e no outono-inverno/primavera-verão (c). (as barras representam o erro padrão da média de quatro repetições).

nos dois períodos (Figura 3c). Esses resultados mostram que para a adubação de solo, o parcelamento desse nutriente, durante todo o ano, é mais vantajoso que sua aplicação somente no período de verão, como comumente é feito.

Apesar da inviabilidade de um grande número de pulverizações, conforme as que foram realizadas neste experimento, os dados permitem concluir que, eventualmente, uma ou mais pulverizações com nitrato de potássio a $25 \%$ podem substituir eficientemente a adubação nitrogenada no solo.

Em relação à próxima safra, esperam-se os efeitos mais positivos, pelo fornecimento de toda a dose de nitrato de potássio nas folhas nos períodos de outono-inverno ou outono-inverno/primavera-verão ou a adubação de folha-solo, na primavera-verão, visto que estes tratamentos foram os que mais contribuíram para o crescimento vegetativo.

\section{CONCLUSÕES}

Em função da época de adubação, no outonoinverno, deve-se dar preferência pela aplicação na folha ou folha-solo. Essa última forma deve ser a preferida quando a adubação se der no período de primaveraverão. Quando as adubações ocorrerem nos dois períodos, qualquer um dos três modos pode ser utilizado.

Apesar da inviabilidade de várias pulverizações, eventualmente, uma ou mais pulverizações com $\mathrm{KNO}_{3}$ podem substituir eficientemente a adubação no solo.

\section{REFERÊNCIAS BIBLIOGRÁFICAS}

ALVES, J. D.; CORDEIRO, A. T.; RENA, A. B. Influência da idade da folha, da concentração de gás carbônico e da temperatura sobre a fotossíntese de diversos germoplasmas de Coffea arabica L. In: CONGRESSO BRASILEIRO DE PESQUISAS CAFEEIRAS, 12., 1985, Caxambu, MG.Anais... Rio de Janeiro: MIC/IBC, 1985. p. 134-135.

AMARAL, J. A. T.Crescimento vegetativo estacional do cafeeiro e suas inter-relações com fontes de nitrogênio, fotoperíodo, fotossíntese e assimilação de nitrogênio. 1991. 139 f. Tese (Doutorado)-Universidade Federal de Viçosa, Viçosa, 1991.

BARROS, R. S.; MAESTRI, M.; VIEIRA, M.; BRAGA, F. L. J. Determinação da área de folhas do café (Coffea arabica L cv Bourbon Amarelo). Revista Ceres, Viçosa, v. 20, n. 107, p. 44-52, jan./mar. 1973.

BREMNER, J. M. Total nitrogen. In: BLACK, C. A. (Ed.). Methods of soil analysis: part 2. Madison: American Society of Agronomy, 1965. v. 1, p. 1149-1178.

CAMARGO, P. N.; SILVA, O. Manual de adubação foliar. São Paulo: Herba, 1975. 258 p.

GARCIA, A. W. R.; PEREIRA, J. M.; SALGADO, A. R.; VENGA, R. Estudo da substituição e,ou, complementação de nutrientes ( N, P,e K) por via foliar. In: CONGRESSO BRASILEIRO DE PESQUISAS CAFEEIRAS, 10., 1983, Poços de Caldas. Resumos... Rio de Janeiro: IBC-GERCA, 1983. p. 215-220. 
KEENEU, D. R.; NELSON, D. W. Nitrogen-inorganic forms. In: PAGE, A. L. (Ed.). Methods of soil analysis. Madison: American Society of Agronomy, 1982. v. 2, cap. 33, p. 643697.

MALAVOLTA, E. Elementos de nutrição de plantas. São Paulo: Agronômica Ceres, 1980.

NASCIMENTO, M. N. do; FALEIROS, S. C.; ALVES, J. D.; FREITAS, R. B. de; MAGALHÃES, M. M. Adubação do cafeeiro com nitrato de potássio via solo e folha no outono-inverno e primavera-verão. In: CONGRESSO DE INICIAÇÃO CIENTÍFICA DA UFLA, 17., 2004, Lavras. Anais... Lavras: UFLA, 2004. CDROM.

QUEIROZ, C. G. S. Distribuição e regulação da atividade da redutase do nitrato no cafeeiro (Coffea arabica L.) 1986. 51 f. Dissertação (Mestrado) - Universidade Federal de Viçosa, Viçosa, 1986.
RENA, A. B.; FÁVARO, J. R. A. Nutrição do cafeeiro via folha. In: ZAMBOLIM, L. Café: produtividade, qualidade e sustentabilidade. Viçosa: UFV, 2000. p. 149-208.

RIBEIRO, A. C.; GUIMARÃES, P. T. G.; ALVAREZ, V. V. H. Recomendações para o uso de corretivos e fertilizantes em Minas Gerais. Viçosa: UFV, 1999. 359 p.

SANTINATO, R.; CAMARGO, R. P. Efeitos da adubação foliar completa no período inicial de frutificação do cafeeiro em formação em diferentes tipos de desfolha. In: CONGRESSO BRASILEIRO DE PESQUISAS CAFEEIRAS, 15., 1989, Maringá, PR. Trabalhos Apresentados... Maringá: UFPR, 1989. p. 213-215.

SANTINATO, R.; PEREIRA, E. M. Efeitos do $\mathrm{KNO}_{3}$ (nitrato de potássio) Haifa, via foliar, em cafeeiros em produção. In: CONGRESSO BRASILEIRO DE PESQUISAS CAFEEIRAS, 22., 1996, Águas de Lindóia. Anais... Brasília, DF: MAA-PROCAFÉ, 1996. p. 130-132. 